\title{
La flota pesquera de altura y gran altura en el puerto de Barcelona. Una historia no contada (1907-1936)*
}

\author{
- Ana I. Sinde Cantorna \\ - Gema Álvarez Llorente \\ Universidad de Vigo
}

\section{Introducción}

Los buques pesqueros de más de cien toneladas de registro bruto (TRB) dedicados a la pesca de arrastre se empezaron a introducir en España a finales del siglo XIX, siendo en los primeros años del siglo XX cuando se produjo el gran despegue de esta nueva flota. ${ }^{1}$ Como consecuencia se modificó la tipología de unidades pesqueras y el sector se abrió de pleno al mundo de la empresa capitalista, ya que su adquisición requería de volúmenes de inversión que no estaban al alcance de los individuos y empresas dedicados a la pesca tradicional. Esto llevó a la entrada de nuevos inversores procedentes, en muchos casos, de sectores afines y que disponían del capital suficiente para acometer la inversión inicial. ${ }^{2}$

* Este artículo forma parte del proyecto "Pesca, conserva y congelado: frontera, organización, instituciones y tecnología en la historia reciente de la pesca española" (HAR2017-88128-R). Nuestro agradecimiento al grupo de investigación GITASP - Innovació Tecnològica al Sistema Productiu - y al Departamento de Historia e Instituciones Económicas de la Universidad de Barcelona por las estadías de investigación realizadas en los cursos 2012-2013 y 2014-2015. Así mismo, agradecer los comentarios hechos por los evaluadores anónimos y el consejo de redacción que han contribuido a mejorar el texto original.

1. Sobre la introducción de los primeros vapores de arrastre pueden consultarse, entre otros, Maiz (1993), Giráldez (1996), López Losa (1997 y 1999), Sinde (2000).

2. La entrada de capital externo para la financiación de las nuevas unidades de pesca no sucedió solo en España. En este sentido, Robinson constata la entrada de empresas del sector naval, de la marina mercante y otros negocios navieros en el capital de las sociedades creadas para la adquisición de trawlers en Inglaterra. Igualmente en el caso alemán y holandés. En el caso alemán cabe destacar las ayudas gubernamentales y, en el holandés, la participación activa en el capital de las nuevas sociedades de la banca y las grandes firmas comerciales (Robinson, 1998, pp. 183-188). 
Estas nuevas unidades, de mayor porte, con casco de hierro o acero y provistas de motores de vapor, incrementaron de forma extraordinaria la capacidad extractiva y permitieron el desarrollo de la actividad en nuevas áreas de pesca alejadas de las zonas tradicionales. Paralelamente, tuvo lugar un cambio importante en lo que respecta al producto obtenido, ya que se capturaban especies para su venta en fresco (su destino no era la industria transformadora). Además, los nuevos volúmenes de producción excedían a los que podían absorber los mercados próximos, como había sucedido hasta el momento. Se hizo imprescindible la expansión de los puntos de venta mediante el acceso a los grandes centros de consumo, no abastecidos hasta ese momento, situados principalmente en el interior de la Península. Esta ampliación de la red de comercialiación no se podría entender sin el ferrocarril, al igual que sucedió en otros países. ${ }^{3}$ Con los medios de transporte tradicionales hubiese sido inviable distribuir por toda la Península cantidades cada vez mayores de producto.

Sobre la expansión de la pesca industrial existen diversos estudios de ámbito regional, que cubren el caso gallego, vasco, asturiano, andaluz y canario, quedando al descubierto el caso del Levante y, más en concreto, lo que afecta al puerto de Barcelona. ${ }^{4}$ Esta falta de trabajos en relación con este particular adquiere gran relevancia dado que Barcelona era uno de los mayores mercados de consumo de España a principios del siglo XX, tanto por volumen como por capacidad adquisitiva de la población, además de ser un referente en el proceso de industrialización que se estaba llevando a cabo en el país. Es por ello que quizás se haya restado importancia a la flota pesquera de este puerto, cuando antes de la Primera Guerra Mundial allí se concentraba la mayor flota de otter trawlers de España. ${ }^{5}$

El objetivo de este trabajo es analizar la pesca de altura en el puerto de Barcelona, considerando los buques y las empresas que lo conformaron y las estrategias seguidas por estas, para así poder establecer la importancia real de dicho subsector en el abastecimiento de la ciudad hasta los años de la Guerra Civil.

Para ello, se utilizaron fuentes de información, tanto primarias como secundarias. Entre las fuentes consultadas caben destacar las siguientes: los re-

3. Para el caso inglés pueden consultarse los trabajos de Robinson (2000) y Wilcox (2012). Para el caso escocés, Coull (1998).

4. Cabría destacar, entre otros, los realizados para el caso gallego por Quiroga (1952), Giráldez (1985 y 1996), Eiroa (1997), Sinde (2000) y Mirás (2005); para el caso vasco, los de Maiz (1993) y López (1997 y 1999); para el caso asturiano, las aportaciones de Ocampo (2002); para Andalucía, los trabajos de Ríos (2002), Giráldez (2002) y Lacomba (2006) y, para Canarias, Martínez (2005 y 2014).

5. Sí se ha abordado el estudio del sector de la marina mercante o, a nivel local, el de la pesca tradicional, pero no así el del sector pesquero de altura. Tal y como recoge Moreno: «[...] aparte de algunas monografías locales, hay unanimidad en afirmar que la historia de la pesca de Cataluña está por hacer. [...] Merecería la pena estudiar la implantación en Barcelona de compañías pesqueras a partir de la segunda década del siglo XX» (Moreno, 2011, p. 121). 
gistros de altas de la contribución industrial de la ciudad de Barcelona, consultados en la sección de Hacienda del Archivo de la Corona de Aragón (ACA) (esta fuente nos ha permitido recabar datos sobre la fecha de inicio de la actividad de las diferentes empresas). Esta información se ha complementado con la obtenida de los registros de sociedades y de buques del Registro Mercantil de A Coruña (RMC) y del Registro Mercantil de Barcelona (RMB). En ambas fuentes, además del objeto social, se ofrece información sobre las personas que integraban las sociedades, así como su porcentaje de participación en las mismas.

Para determinar la flota existente en el puerto de Barcelona, se consultó la Lista Oficial de Buques de Guerra y Mercantes de la Marina Española (LOB), que nos permitió conocer los buques existentes en el puerto de Barcelona y sus características básicas - año y lugar de construcción, año de su primera matrícula, tonelaje (bruto y neto), metros de eslora, potencia, tipo de actividad a la cual se dedicaba, etc., así como el nombre de su propietario y el lugar donde se encontraba matriculado en un momento determinado-. No obstante, una de las limitaciones de esta fuente es precisamente que indica el lugar de matrícula de la embarcación, pero esta no tiene por qué coincidir con el puerto donde opera. Es por ello que se complementó con la consulta de la sección de «Movimientos del Puerto» del diario de La Vanguardia, entre los años 1906-1930. Así, pudimos registrar las entradas y salidas de los pesqueros que usaban el puerto de Barcelona como centro de operaciones y el volumen de la flota que realizaba allí sus descargas, independientemente del lugar en el que se encontrasen matriculados.

Por último, la consulta de los fondos de la Junta de Obras del Puerto (JOP), depositados en el Archivo del Museo Marítimo de Barcelona (AMMB), nos permitió disponer de información sobre las grandes casas armadoras asentadas en el puerto de Barcelona y sobre la situación del sector extractivo en la ciudad.

\section{Instalación y crecimiento de la flota pesquera de altura en el puerto de Barcelona, 1907-1914}

Como ya se ha señalado, el arrastre a vapor empezó a introducirse a finales del siglo XIX en España. En Barcelona fue en el año 1907 cuando arribaron los primeros barcos y se establecieron definitivamente en este puerto. Los vapores llegados en los primeros años lo hicieron siguiendo la estrategia expansiva que habían iniciado los armadores de puertos del norte de la Península, principalmente coruñeses, en el año 1906. En este sentido, el diario de La Vanguardia, en su edición del 22 de agosto de 1907, recogía: 
La crisis que está atravesando la industria dedicada a la pesca en las costas del Cantábrico y Atlántico ha motivado que algunos armadores de vapores pesqueros hayan decidido buscar nuevos parajes donde desarrollar su industria. Algunos han optado por enviarlos al Mediterráneo.

A partir del año 1904 en el puerto de A Coruña se había constituido una de las flotas más importantes de España. Sin embargo, en el año 1906, debido a la gran capacidad de captura alcanzada, aparecieron los primeros síntomas de sobreexplotación en sus caladeros tradicionales y también algunos problemas para situar en los mercados finales la ingente cantidad de pescado capturado. El destino final de este producto eran los mercados próximos a la ciudad y, sobre todo, Madrid. Asimismo, debemos señalar que durante el año 1907 en el puerto coruñés se produjeron huelgas continuas que dificultaron el desarrollo de la actividad y que, en muchos casos, fueron el detonante para tomar la decisión de cambiar la localización de la actividad.

En este contexto, a finales de 1906 se llevaron a cabo las primeras prospecciones en búsqueda de nuevos caladeros. Una de las empresas del puerto coruñés, Tejero, Mariñas y Cía, envió uno de sus vapores a las costas africanas. El éxito obtenido por la expedición provocaría el desplazamiento de más unidades a esas aguas. ${ }^{6}$ Sin embargo, los días empleados en regresar al puerto de A Coruña desde los nuevos caladeros, para luego reexpedir la mercancía a mercados alejados del mismo, se convirtió en un nuevo problema. Para afrontarlo, los armadores adoptaron la decisión de asentarse en otros puertos que facilitasen tanto el acceso a las nuevas zonas de pesca como a los mercados finales.

Es importante resaltar que no sirve cualquier puerto para albergar a la nueva flota. Podemos destacar tres factores clave para el asentamiento y/o localización de la flota de arrastre: las condiciones del puerto, la disponibilidad de caladeros y el acceso a los mercados finales. Las condiciones del puerto son fundamentales, dado que se precisan una serie de servicios anexos imprescindibles para el desarrollo de la actividad, así como muelles de determinado calado. ${ }^{7} \mathrm{La}$ disponibilidad de caladeros determinaba el nivel de captura, por tanto, la producción de la empresa. El acceso rápido a los mercados finales garantizaba la posibilidad de vender el producto en condiciones óptimas y, consecuentemente, la calidad de este y los ingresos de la empresa. ${ }^{8}$

6. «El vapor pesquero Mary que había ido a las costas de África para ensayar los procedimientos de pesca que se usan aquí, ha regresado a este puerto - A Coruña - abarrotado de pesca. Trae la respetable suma de 11.000 merluzas. En vista del éxito obtenido, muchos vapores se disponen a salir para operar en las costas de África. Gran parte de la pesca recogida por el Mary ha sido enviada a Madrid» (La Vanguardia, 3 de enero de 1907).

7. Existen diferentes trabajos en los que se analizan los requerimientos indispensables de un puerto para poder abastacer esta nueva flota, por ejemplo, Compan (1975), Robinson (1996), Mumby-Croft (2001), Sinde y Diéguez (2006),

8. La situación del transporte de pescado en España en esos años ha sido estudiada por Sinde (1999) y Ocampo (2003). 
Teniendo en cuenta estas circunstancias, una parte de la flota gallega optó por el desplazamiento tanto a puertos vascos como del sur de la Península. Los puertos vascos estaban situados cerca de los caladeros del golfo de Vizcaya y bien comunicados con el mercado madrileño y barcelonés. Mientras que los puertos del sur facilitaban el acceso a aguas africanas y disponían de conexión ferroviaria con Madrid. Así, en 1907, Tejero, Mariñas y Cía establecen una sucursal en Cádiz, desde donde abastecían el mercado del sur a la vez que realizaban envíos al mercado madrileño. Esa empresa no sería la única que optó por esta estrategia para expandir el radio de acción y su mercado final. Otra de las empresas más importantes de A Coruña, Pescaderías Coruñesas, desplaza parte de su flota a puertos vascos para abastecer desde allí al mercado madrileño.

Los puertos vascos y los situados en el sur peninsular no fueron los únicos destinos. Hubo una serie de empresas que optaron por realizar los desembarcos directamente en el puerto de Barcelona. Esta ciudad era el principal centro de consumo español, básicamente abastecido por la flota tradicional asentada en la costa mediterránea, con unos niveles de renta en aumento y una demanda creciente, debido al desplazamiento de la población a dicha ciudad. El consumo de pescado fresco en la capital catalana se incrementó durante todo el período objeto de estudio, pasando de 2.006 .903 kilogramos en el año 1900 a 18.509 .646 kilogramos en $1929 .{ }^{9}$

Los envíos de pescado fresco desde los puertos gallegos a este gran mercado, en condiciones óptimas, eran inviables en estos años, sobre todo en las épocas calurosas del año, debido al tiempo empleado en el desplazamiento -más de cuatro días - y a las condiciones en las que se realizaban los envíos ferroviarios - en vagones convencionales, sin ningún tipo de adaptación. ${ }^{10}$

Una ventaja añadida que ofrecía la ciudad catalana era que disponía de un puerto en el que ya existían los servicios imprescindibles para el asentamiento de este nuevo tipo de flota. Condiciones que en esos años no reunían otros puertos. Recordemos que en los años veinte, cuando se produjo el desplazamiento de armadores gallegos al puerto de Cádiz, uno de los mayores problemas con los que se encontraron fue la falta de servicios portuarios. ${ }^{11}$

Dentro de las empresas que trasladaron su actividad del puerto de A Coruña al de Barcelona destacaría Pesquerías Gallegas S.A. ${ }^{12}$ En 1907 envió el

9. Anuari Estadístic de la Ciutat de Barcelona (1902) y Gaceta Municipal de Barcelona (1928-1930). Este aumento estuvo justificado por la evolución del número de habitantes y por una oferta creciente del producto. En el año 1900 se registraban 537.354 habitantes en la ciudad, mientras que, en 1931, se alcanzaban los 823.568 (Gaceta Municipal de Barcelona, febrero 1927).

10. Sinde (2014).

11. Giráldez (2002).

12. Pesquerías Gallegas S.A. fue constituida en A Coruña en 1906, con un capital social de 230.000 pesetas, repartido en 92 acciones de 2.500 pesetas. Tenía por objeto social la indus- 
primero de los barcos, el Avispa, al que se unió el vapor Araña en 1908 y el Tiburón en $1909 .{ }^{13}$ Cabe resaltar que la compañía, en el momento inicial, quiso acceder a la venta directa del producto en el mercado barcelonés, estrategia que seguía en el puerto de A Coruña, ciudad en la que controlaba la fase de transformación y venta mediante la participación de algunos de sus socios en firmas dedicadas a dichas actividades. ${ }^{14}$

No obstante, las barreras de entrada existentes para la venta del pescado fresco en la capital imposibilitaron la iniciativa. El mercado estaba controlado por los vendedores al por mayor con barraca o casilla en el Mercado Central de Pescado, donde obligatoriamente debían vender el pescado en subasta a la baja los vapores llegados a puerto. ${ }^{15} \mathrm{Al}$ no existir libre entrada en el mercado de venta del pescado fresco, se propició la creación de monopolios por parte de los vendedores asentados y con derecho reconocido, que les permitió ejercer un gran control sobre la oferta. Así, tal y como recoge La Vanguardia de 13 de julio de 1907:

El vapor Avispa de la matrícula de A Coruña, llegado ayer a este puerto, condujo 40 toneladas de pescado fresco, procedente de Canarias, para ser vendido en esta ciudad. El consignatario del vapor había obtenido de la Alcaldía autorización para proceder a la venta del pescado en el mercado del Borne, pero a la vista de que los vendedores al por mayor del citado artículo se oponían, se puso de acuerdo con ellos siendo vendido finalmente en subasta en el mercado de la calle Ocata. ${ }^{16}$

tria de la pesca y formaban parte de la misma Ramón Canosa Cierto (14 acciones), Narciso Obanza Alonso y Elena Miranda Santos (14 acciones), Leonardo Rodríguez Díaz y Pilar Miranda Santos (14 acciones), Hnas Rodríguez Díaz (12 acciones), Vicente Galiana Puchol (12 acciones), Jacinto Guisande Pereira (12 acciones), Manuel Sollozo Fernández (4 acciones), Pedro Pan Gómez (4 acciones), Manuel Rodríguez Díaz y Ramona Barahona Martínez (3 acciones) y Antonio Alonso Domínguez (3 acciones) (RMC, Registro Sociedades, libro 14, hoja 357, folio 123).

13. «La floreciente industria pesquera coruñesa, si no se muere, va a sufrir por lo menos un golpe sensible. Los vapores de la Sociedad Pesquerías Gallegas no tardarán en marchar a pescar lejos, ya están en Barcelona el Avispa y, en Bilbao, el Esperanza y el Jaboo, y en Asturias algunas parejas» (Vida Marítima, 10 de diciembre de 1906).

14. Esta empresa tenia control sobre la fase de transformación a través de la participación de su presidente-director, Leonardo Rodríguez Díaz, y de Narciso Obanza Alonso en la sociedad La Iniciadora S.A., constituída en A Coruña en 1906 con el objeto de dedicarse a la industria de la conserva y la salazón de pescados y a la fabricación de bacalao (Vida Maríti$m a, 20$ de diciembre de 1906). Asimismo, buscó disponer de cierto control sobre la fase de comercialización de sus productos a través de la participación en la sociedad Juan Carreras Presas y Cía, constituída en 1907 para la venta de pescado fresco y conservas en Madrid, de la que formaban parte Juan Carreras Presas, J. García García, Tejero, Mariñas y Cia y Pesquerías Gallegas S.A. (RMC, Registro Sociedades, libro 14, hoja 347, folio 349).

15. Sobre los agentes implicados en la distribución de pescado fresco en la ciudad de Barcelona puede consultarse Sinde (2014).

16. En esos años el Mercado Central de pescado estaba situado en la calle Ocata. En 1908 regresará al mercado del Borne, donde ya se había asentado el mercado al por mayor de pescado entre 1884 y 1899, y donde permanecerá hasta 1921, cuando se traslada a la calle Si- 
Cabe señalar que, aunque estos buques aparecen recogidos en los años iniciales en las listas oficiales de buques como propiedad de la empresa Pesquerías Gallegas S.A., posteriormente, pasaron a ser gestionadas por la sociedad Canosa, Trillo y Cía, constituída también en 1906 en A Coruña por Ramón Canosa Cierto, J. Trillo Durán y J. M. Pernas Rodríguez. ${ }^{17}$ Entre ambas sociedades existía una gran interrelación, ya que el gerente de Canosa, Trillo y Cía sería Vicente Galiana Puchol, que, junto con Ramón Canosa, eran a su vez socios de Pesquerías Gallegas S.A. (consúltese figura 1 del anexo). Asimismo, en una carta escrita al periódico El Noroeste, el 3 de enero de 1914, por Ramón Canosa, se recoge que fue «Vicente Galiana el encargado de adquirir los vapores de la empresa - Araña, Avispa y Tiburón-en Hull».

El apellido Canosa será uno de los más vinculados a los armadores pesqueros barceloneses, manteniendo la actividad, a través de sociedades diferentes, hasta los años setenta, convirtiéndose en la iniciativa más longeva del sector. A través de la firma Canosa, Trillo y Cía se estableció definitivamente en el puerto de Barcelona a partir de 1908, cuando la sociedad se dió de baja en el Registro Mercantil de A Coruña y trasladó su domicilio social a Barcelona. ${ }^{18}$

En 1907 se trasladaron otros dos vapores coruñeses al puerto de Barcelona: Lord Roberts y Robin, matrículados en A Coruña y propiedad de Elvira Truán, pero gestionados por la sociedad Hijos de Tomás Guyatt SRC, constituida en 1907 en A Coruña con el objeto social de «provisión de agua a barcos en el puerto de A Coruña», siendo uno de los socios de esta Henry Guyatt, el apoderado de Elvira Truán. ${ }^{19}$ En 1909 la sociedad formada por Henry Guyatt Deusto, Eduardo Guyatt López y Enrique Gilard se quedaría con el buque Robin. ${ }^{20}$ Posteriormente, el Lord Roberts pasó a ser propiedad de Luis Delclaux, pero gestionado por la casa Freixas.

En el año 1908, la sociedad coruñesa Eduardo Somoza y Cía envía a su vapor Rosalind al puerto de Barcelona, desde donde operó hasta el año 1912, cuando fue vendido a Pesquera Malagueña S.A. ${ }^{21}$ Otra de las empresas coru-

cilia (hoy calle Wellington) hasta su instalación en Mercabarna en octubre de 1983 (Sinde, 2014).

17. En este sentido, a partir de 1911 el barco deja de pertenecer a Pesquerías Gallegas S.A. y pasa a Canosa, Trillo y Cía (LOB, 1906-1911). Esta sociedad fue constituida con un capital de 55.000 pesetas, cuyo $50 \%$ pertenecía a Ramón Canosa, mientras que J. Trillo había invertido 20.000 pesetas y J.M. Pernas, 7.500 pesetas (RMC, Registro Sociedades, libro 14, folio 176).

18. Veiga (1974).

19. Elvira Truán formará parte de la Cooperativa de Vapores de La Coruña, constituida el 24 de diciembre de 1906, y en la que la representa como su apoderado Henry Guyatt (RMC, Registro Sociedades, libro 15, hoja 395, folio 243).

20. RMC, Registro Buques, libro 2, hoja 41, folio 80.

21. Eduardo Somoza y Cía S.R.C. se constituyó en A Coruña en 1905, con el objeto de «dedicarse a la pesca y por consiguiente a la compra-venta al por mayor y por menor de toda clase de pescado fresco». Con un capital de 90.000 pesetas repartido a partes iguales entre sus tres socios: E. Somoza Tenreiro, E. del Río Santos y L-Lavin Cortes (RMC, Registro Sociedades, libro 14 , hoja 345 , folio 66 ). 
ñesas que se desplazó a Barcelona fue la de Vicente Nieto, que a partir de 1908 adopta dicho puerto como punto de desembarco de las capturas de su vapor Boadicea. ${ }^{22} \mathrm{El}$ paso de esta empresa por el puerto de la ciudad condal resultó breve, ya que dejó de realizar desembarcos en el año 1909.

A partir de 1909 se trasladó definitivamente al puerto de Barcelona el vapor Bohemio, matriculado en Gijón en 1907 por Alfonso Rodríguez del Valle. ${ }^{23}$ Y, en 1908, el vapor Kelvin. Este armador estuvo, como veremos, fuertemente vinculado a diferentes sociedades barcelonesas y formó parte de los principales órganos representativos del sector.

Tras los años iniciales entraron en el nuevo negocio empresarios catalanes, adquiriendo en muchos casos los vapores traídos por los gallegos y, en otros, incorporando nuevas unidades pesqueras. Así, Pedro Freixas Pons será el consignatario del Lord Roberts de Elvira Truán, y adquirirá en 1910 el vapor pesquero Pedro y, en 1913, el María. ${ }^{24}$ Su padre, Pedro Freixas Farigola, provenía del mundo de la pesca, siendo a finales del siglo XIX el presidente de la Asociación de Patronos Pescadores. ${ }^{25}$ Su madre, María Pons Olivari, había adquirido una casilla para la venta al por mayor de pescado en el Mercado Central en el año 1901. Paralelamente, los hermanos Francisco y Ramón Freixas Pons constituyen en 1906 la sociedad colectiva Freixas Hermanos, cuyo capital ascendía a 12.000 pesetas, aportado a partes iguales y cuyo objeto social serían «las consignaciones, comisiones y representaciones». ${ }^{26}$ Bajo esta razón social pasarán a gestionar los vapores tras la muerte de Pedro Freixas Pons en el año 1914.

Además del caso de Freixas, cabe señalar la iniciativa protagonizada por empresarios catalanes en el año 1907, a través de la constitución en Barcelona de la firma Sociedad Anómina Catalana de Pesca, concretamente el 26 de febrero de 1907, e impulsada por Francisco Palau Ferrer, quien había reali-

22. Vicente Nieto formará parte de diversas sociedades en A Coruña, liquidando la última Nieto y Pérez y adquirendo todos los activos y pasivos, entre ellos el buque (RMC, Registro Buques, libro 2, hoja 24, folio 47).

23. Real Orden de 14 de octubre de 1907.

24. El pesquero Lord Roberts sigue figurando en las listas oficiales de buques como propiedad de Elvira Truán hasta el año 1914, cuando es adquirido por Luis Delclaux. No obstante, en todas las referencias recogidas en el diario La Vanguardia se le atribuye su «propiedad» a la casa Freixas.

25. Así aparece recogido en una instancia enviada al gobernador civil de la provincia desde La Unión de Pescadores de Barcelona el 30 de julio de 1896, en la que se reclamaba mayor espacio en el puerto para las actividades pesqueras (AMMB, fondos JOP, H-1573, carpeta 6).

26. Pedro Freixas Farigola y María Pons Olivari eran los padres de Pedro, Juan, Francisco y Ramón Freixas Pons. El primero de los hermanos fallece con 24 años en diciembre de 1914 (La Vanguardia, 1 de enero de 1915). En el año 1915 se incorporará a la sociedad Juan Freixas Pons, aportando igualmente 6.000 pesetas (RMB, Registro de sociedades, libro 67, hoja 6628 , folio 67$)$. 
zado estudios de la pesca en la costa africana. ${ }^{27}$ Esta sociedad adquirirá el vapor Blanes, que operará en el puerto de la Ciudad Condal durante dos años. ${ }^{28}$ A partir de 1909 la embarcación pasa a formar parte de la flota auxiliar de la marina de guerra en el norte de África, ${ }^{29}$ lo que pone de relieve la implicación de los armadores catalanes en la apertura de los caladeros africanos. Siendo el delegado en África de la sociedad, Ramón Compte, junto con el representante del Ministerio de Marina español y el representante africano, llegaron a un acuerdo el 17 de enero de 1909 para garantizar el acceso y seguridad de los pesqueros en aguas africanas.

En 1909 J. Vidal Barraquer incorporó su primer buque pesquero de altura, el Montserrat II, al que se le unieron el Mercè y el Misericordia, en 1910 y 1914, respectivamente. En 1913, empezó a operar el vapor Fantasma, perteneciente a la Sociedad Pesca y Comisiones y cuyo consignatario era Pablo Roig.

Paralelamente al crecimiento paulatino del número de unidades que pasan a operar desde el puerto de Barcelona, en mayo de 1910 se constituyó legalmente en la Ciudad Condal un sindicato de fomento marítimo, con la denominación de Pesca Marítima Nacional —Demarcación del Mediterráneo-, filial de la Liga Marítima Española. El presidente del mismo era Vicente Galiana; el vicepresidente, Plácido R. Martos; el secretario general, Ramón Compte, y los vocales delegados, Alfonso R. del Valle, Emilio Borrás y Federico Delclaux, pasando a formar parte del mismo los vapores Avispa, Araña, Tiburón, Lord Roberts, Bohemio, Montserrat, Kelvin y Rosalind.

En el año 1914, tuvo lugar una reestructuración organizativa del sector. Cabe destacar la disolución de una de las empresas pioneras en el puerto barcelonés: Canosa, Trillo y Cía. Sus socios se separaron, aunque continuaron la actividad en dicho puerto a través de dos sociedades independientes (consúltese figura 1 del anexo). Por una parte, uno de los socios, J. Trillo Durán, y el gerente hasta ese momento de la misma, Vicente Galiana, junto con Alfonso Rodríguez del Valle constituyen la sociedad comanditaria Trillo, Galiana y Cía. La nueva firma se quedó con los vapores de su predecesora Avispa, Araña y Tiburón - y adquirió dos nuevos buques, el Esla y el Scomber, y pasó a convertirse en la primera casa armadora de pesqueros en el puerto. Por otra parte, Ramón Canosa se asoció con Jesús Reboredo Fraga a través de la razón social de Canosa y Reboredo y adquirieron en Hull tres nuevos vapores para el desempeño de su actividad: Habana, Santiago y Villa de Cee.

Con las nuevas adquisiciones en el año 1914, en el puerto de Barcelona operaban regularmente 17 vapores de arrastre de gran porte (véase tabla 1),

27. La Ilustració Catalana, 22 de julio de 1908. Dicha sociedad se inscribe en el Registro Mercantil de Barcelona el 11 de marzo de 1907 (RMB, Registro de sociedades, libro 71, hoja: 7.030, folio 2).

28. Se le asigna señal distintiva en octubre de 1907 (Real Orden de 14 de octubre de 1907).

29. Real Orden del Ministerio de Marina (El Siglo Futuro, 25 de febrero de 1909). 
TABLA 1 - Empresas y flota en el puerto de Barcelona hasta el año 1914.

\begin{tabular}{|c|c|c|c|c|c|}
\hline Buques operativos & $\begin{array}{l}\text { Año } \\
\text { const. }\end{array}$ & $\begin{array}{l}\text { Año } \\
\text { incorp. }\end{array}$ & $\begin{array}{l}\text { Material } \\
\text { casco }\end{array}$ & TRB & $\begin{array}{l}\text { Empresa propietaria } \\
\text { en } 1914\end{array}$ \\
\hline Avispa (ex-Othello) & 1901 & 1907 & Acero & 240 & Trillo, Galiana y Cía \\
\hline Araña (ex-Dane) & 1903 & 1908 & Acero & 267 & \\
\hline Tiburón & 1906 & 1909 & Acero & 207 & \\
\hline Esla (ex-Gwyneth) & 1908 & 1914 & Acero & 251 & \\
\hline Scomber & 1909 & 1914 & Acero & 269 & \\
\hline Habana (ex-Crusader) & 1904 & 1914 & Acero & 259 & Canosa y Reboredo \\
\hline Santiago (ex-Franklin) & 1905 & 1914 & Acero & 275 & \\
\hline Villa de Cee (ex-Dynamo) & 1905 & 1914 & Acero & 275 & \\
\hline Pedro (ex-Norman) & 1903 & 1910 & Acero & 270 & Pedro Freixas Pons \\
\hline Lord Roberts & 1900 & 1912 & Acero & 217 & Francisco Freixas \\
\hline María (ex-Saxon) & 1907 & 1913 & Acero & 347 & $\begin{array}{l}\text { Pons } \\
\text { Juan Freixas Pons } \\
\text { Ramón Freixas Pons }\end{array}$ \\
\hline Kelvin & 1898 & 1908 & & 184 & Alfonso R. del Valle \\
\hline Bohemio & & 1909 & & 141 & \\
\hline Fantasma & 1904 & 1913 & Acero & 253 & $\begin{array}{l}\text { Sociedad Pesca } \\
\text { y Comisiones }\end{array}$ \\
\hline Montserrat II & 1906 & 1909 & Acero & 208 & J. Vidal Barraquer \\
\hline Mercè & 1897 & 1910 & Hierro & 169 & \\
\hline Misericordia (ex-Sea King) & 1902 & 1914 & Acero & 228 & \\
\hline Buques no operativos & $\begin{array}{l}\text { Año } \\
\text { const. }\end{array}$ & $\begin{array}{c}\text { Año } \\
\text { incorp. }\end{array}$ & $\begin{array}{c}\text { Material } \\
\text { casco }\end{array}$ & TRB & Empresa propietaria \\
\hline Boadicea (ex-Once Amigos) & 1899 & 1908 & & 193 & $\begin{array}{l}\text { V. Nieto lo vende a } \\
\text { R. Carranza en } 1914\end{array}$ \\
\hline Rosalind & & 1908 & & 224 & $\begin{array}{l}\text { E. Somoza lo vende } \\
\text { a Pesquera } \\
\text { Malagueña en } 1912\end{array}$ \\
\hline Robin & & 1907 & & 134 & $\begin{array}{l}\text { Elvira Truán, lo } \\
\text { vende a Henry } \\
\text { Guyatt y Cía en } 1909\end{array}$ \\
\hline Blanes & & 1907 & & 122 & $\begin{array}{l}\text { Sociedad Catalana } \\
\text { de Pesca S.A.(desde } \\
1909 \text { desplazado a } \\
\text { aguas africanas para } \\
\text { labores de seguridad) }\end{array}$ \\
\hline
\end{tabular}

Fuente: Elaboración propia a partir de las LOB de los años correspondientes, Thompson et al. (1999); Memoria Comercial de la Cámara de Comercio y Navegación de Barcelona de los años 1913 y 1914 y Anuario Estadístico de la Ciudad de Barcelona de 1914.

con lo que superaba a los 14 existentes en el País Vasco o a los 10 que se amarraban en Galicia. ${ }^{30}$

30. López (1999, p. 234). 


\section{El desmantelamiento de la flota pesquera de altura, 1914-1919}

La Primera Guerra Mundial tuvo una dimensión claramente económica que afectó no solo a las potencias beligerantes, sino también a las neutrales, entre las que se encontraba nuestro país (recordemos que España declaró su neutralidad el 7 de agosto de 1914). Los países neutrales se beneficiaron de forma extraordinaria de la coyuntura, aunque también sufrieron en parte la tragedia de la guerra. ${ }^{31}$ En este sentido, con el inicio de la Primera Guerra Mundial el sector pesquero de altura y gran altura español vivió un período de fuerte crisis. La escasez de carbón provocó un incremento en los gastos de explotación de las empresas, en muchos casos insostenibles. Muchos de los caladeros explotados por la flota española quedaron dentro de la zona de conflicto, con lo que se restringían las aguas en las cuales poder desempeñar la actividad, o se incrementaba de forma extraordinaria la cuantía a desembolsar por los seguros marítimos. Estas circunstancias, sumadas a los elevados precios que se pagaban en el mercado internacional por los vapores de arrastre, con objeto de incorporarlos como flota de apoyo a la marina de guerra de los países en conflicto, llevaron a un proceso de desinversión en el sector con la venta masiva de buques. ${ }^{32}$

Los problemas se empezaron a manifestar al inicio del conflicto. Así, ya en agosto de 1914, los armadores comienzan a expresar las dificultades existentes para el desarrollo de la actividad debido, principalemte, al incremento registrado por los costes de producción. ${ }^{33} \mathrm{~A}$ pesar de las penurias y de que en ocasiones los pesqueros permaneciesen amarrados debido a que no podían suministrarse de carbón, durante el año 1915 solo dejó el puerto de Barcelona el pesquero Kelvin. No obstante, los problemas para pertrechar los buques continuaron, lo que llevó a muchos armadores a tomar la decisión de deshacerse de los vapores, al igual que sucedió en otros puertos españoles, tanto con buques pesqueros como mercantes. ${ }^{34}$

31. García Domingo (2007, p. 125).

32. Sinde (2000).

33. Tal y como se recoge en el diario de La Vanguardía, del 22 de agosto de 1914: «En la visita hecha al Gobernador Civil por la delegación de Pesca Marítima y comisión de armadores, don Alfonso R. del Valle, Ramón Canals, Emilio Borrás, Luis Delclaux y Pedro Freixas Pons, se hizo presente que ante el alza persistente de las primeras materias empleadas en dicha industria del mar, habiéndose visto obligados al amarre de los vapores Mercé y Santiago, y en evitación del amarre total y paralización de la industria pesquera de altura, tanto por el encarecimiento de las materias primas, como por las trabas administrativas y fiscales, reiteran el ruego nacional formulado por las clases pesqueras de toda España, solicitando al gobierno la inmediata implantación de los beneficios señalados por el artículo 32 y 182 del Reglamento-ley de protección de las industrias marítimas con objeto de evitar dejen de importarse diariamente más de 20 toneladas de pescado fresco con destino al abastecimiento de la plaza de Barcelona y mercados interiores».

34. Para el caso de la pesca, pueden consultarse los trabajos de Giráldez (1996), Sinde (2000). Para la marina mercante, los de Valdaliso (1991) y García Domingo (2007) para el caso catalán. 
A principios del año 1916 se enajenará más de la mitad de la flota afincada en el puerto de Barcelona, concretamente, 9 de los 16 vapores pesqueros de dicho puerto. Así, tal y como recoge La Vanguardia de 26 de enero de 1916:

(...) en breve llegará a esta ciudad el personal que ha de hacerse cargo de los vapores pesqueros Habana, Villa de Cee, Esla, Santiago, Avispa, Mercè, Fantasma, Bohemio y Tiburón, vendidos como dijimos oportunamente a casas navieras del extranjero.

Del anterior grupo de pesqueros, cinco tuvieron como destino la armada rusa con el objetivo de hacer frente a la guerra submarina iniciada por Alemania. Con el cambio de estrategia de combate en la contienda, el ejército ruso reaccionó tarde y, ante la imposibilidad de construir dragaminas a tiempo, optaron por la transformación de vapores pesqueros para cumplir dicha función. A finales de 1915 los agentes rusos en Europa comenzaron la búsqueda de vapores pesqueros con menos de 10 años, con potencias entre $400 \mathrm{y}$ 500 caballos y que fuesen capaces de acoger al menos a 30 hombres. ${ }^{35}$ El día 8 de enero de 1916 compraron todos los vapores de la firma Canosa y Reboredo - Habana, Villa de Cee y Santiago - y dos de la empresa Trillo, Galiana y Cía - Avispa y Esla- (véase tabla 2). ${ }^{36}$

Como ya se ha señalado, esta situación de venta de buques al extranjero se estaba produciendo no solo en el sector pesquero, sino también en el de la marina mercante, en un momento en el que España atravesaba fuertes problemas de abastecimiento, principalmente de carbón y trigo. En este contexto, se promulga el Real Decreto de 7 de enero de 1916, por el que se prohibía la venta a extranjeros de buques españoles de más de 500 toneladas y con menos de 15 años de antigüedad para los buques de hierro o acero y 10 años para los de madera. El objetivo básico era disponer de flota mercante nacional suficiente para realizar los transportes. No obstante, esas condiciones, inicialmente, excluían a los pesqueros, dado que no alcanzaban dicho tonelaje, y en ese mes de enero se efectúan las primeras ventas.

Ante esta situación, el Gobierno trató de evitar la desinversión a través de la ampliación de la prohibición de vender buques a extranjeros. Así, tras la promulgación de una Real Orden en 1916, pasaba a incluirse en la prohibición también a los buques pesqueros. Este hecho llevó a los armadores a tomar el acuerdo de amarrar la flota desde el 1 de marzo de 1916 como medida de protesta ante la redacción de dicha Real Orden. Su situación se hacía in-

35. Mitickov y Lapshin (2011, p. 874).

36. Estos buques serían entregados a la Armada rusa entre el 7 y el 12 de julio de 1916, después de ser habilitados como dragaminas en Newport, en el astillero Mardew, Carnew \& $\mathrm{C}^{\mathrm{a}}$ (Mitickov y Lanpshin, 2011). 
TABLA 2 - Destino de los vapores pesqueros del puerto de Barcelona hasta la Primera Guerra Mundial.

\begin{tabular}{|c|c|c|}
\hline Buque & $\begin{array}{l}\text { Año } \\
\text { baja }\end{array}$ & Destino \\
\hline Avispa (ex-Othello) & 1916 & Vendido a Russian Navy № T28 (1) (2) (3) \\
\hline Araña (ex-Dane) & 1917-18 & Vendido a la Marine Nationale Francaise (Annibal) (1) \\
\hline Tiburón & 1916 & Vendido a empresa extrajera (3) \\
\hline Esla (ex-Gwyneth) & 1916 & Vendido a Russian Navy № T27 (2) (3) \\
\hline Scomber & 1918 & $\begin{array}{l}\text { Vendido a Transports Maritimes et Marine Merchande } \\
(\text { Annibal) (7) }\end{array}$ \\
\hline Habana (ex-Crusader) & 1916 & Vendido a Russian Navy № T29 (1) (2) (3) \\
\hline Santiago (ex-Franklin) & 1916 & Vendido a Russian Navy № T26 (1) (2) (3) \\
\hline $\begin{array}{l}\text { Villa de Cee } \\
(\text { ex-Dynamo) }\end{array}$ & 1916 & Vendido a Russian Navy № T25 (1) (2) (3) \\
\hline Pedro (ex-Norman) & 1914-18 & Desaparecido durante la Gran Guerra \\
\hline Lord Roberts & --- & Cambia el nombre a Luis en el año 1917 \\
\hline María (ex-Saxon) & 1919 & $\begin{array}{l}\text { Transformado a cabotaje y vendido a la Cía Marítima } \\
\text { "Iberia" de San Sebastián (1) }\end{array}$ \\
\hline Bohemio & 1916 & Vendido a empresa extranjera (3) \\
\hline Fantasma & 1916 & $\begin{array}{l}\text { En febrero parte rumbo a Génova y con pabellón italiano } \\
\text { (3) (4) }\end{array}$ \\
\hline Kelvin & 1915 & Deja de operar en el puerto de Barcelona en ese año (5) \\
\hline Montserrat II & $1917-18$ & Vendido al extranjero (Serieux) \\
\hline Mercè & 1916 & Vendido a empresa naviera italiana (3)(6) \\
\hline $\begin{array}{l}\text { Misericordia } \\
(\text { ex-Sea King) }\end{array}$ & $1917-18$ & Vendido a la Marine Nationale Francaise (Sèveré) (1) \\
\hline
\end{tabular}

Fuentes: Elaboración propia a partir de: (1) Thompson et al. (1999); (2) Mitickov y Lapshin (2011); (3) La Vanguardia, 26 de enero de 1916, p. 14; (4) La Vanguardia, 20 de febrero de 1916, p. 17; (5) La Vanguardia, año 1915; (6) La Vanguardia, 7 de enero de 1916, p. 4; (7) www.fleetwood-trawlers.info

sostenible, como ellos mismos manifestaban: «... al precio de 110 pesetas que pagamos hoy el carbón nos es imposible habilitarnos y nuestra ruina sería completa si continuáramos haciéndolos navegar». ${ }^{37}$

Salvo durante los períodos de protestas, la flota que aún no había sido vendida estuvo operativa hasta el verano de 1917. En esa época los vapores seguían operando desde el puerto de Barcelona, pero dejaron la actividad pesquera para dedicarse al comercio de cabotaje de altura. En este sentido, tal y como recoge la publicación Vida Marítima del 15 de diciembre de 1921:

(...) Las varias empresas domiciliadas en Barcelona en 1914 liquidaron casi por completo su flota, bien por las ventas al extranjero o por habilitar sus embarca-

37. La Vanguardia, 10 de febrero de 1916. 
ciones para el tráfico costero con los cercanos puertos franceses, entonces más remunerador.

\section{El segundo renacer de los años veinte}

Una vez finalizada la Gran Guerra, volvió a retomarse el negocio, en muchos casos por parte de armadores que habían abandonado o reducido la actividad durante los años anteriores, caso de Canosa, Galiana o Freixas (véase tabla 3). Así, lo expone el propio Vicente Galiana en el documento de solicitud de la autorización para levantar una construcción en terrenos de la tercera alineación del muelle de Levante, con el objeto de «poder reanudar la industria pesquera a que se había dedicado hace algunos años y tuvo que interrumpir a causa de la Guerra». ${ }^{38}$

Como los buques que no habían sido vendidos se habían transformado para el tráfico de cabotaje, fue preciso reinvertir nuevamente en flota. A partir de 1922 se empezaron a matricular nuevas embarciones para retomar la actividad y, a mediados de esa década, en Barcelona se amarraba una de las flotas pesqueras de altura y gran altura más modernas de España, propiedad de cinco casas armadoras que sumaban un TRB total de 5.609 (veáse tabla 4). Este puerto siguió manteniéndose entre los más destacados del país; en el año 1922 existían en España 45 vapores pesqueros, 14 de ellos operando desde esta ciudad. ${ }^{39}$

TABLA 3 - Solicitudes y concesiones de espacios en el muelle de Levante.

\begin{tabular}{lcc}
\hline \multicolumn{1}{c}{ Empresa } & Fecha solicitud & Fecha concesión \\
\hline Canosa & $12 / 04 / 1021$ & $20 / 06 / 1921$ \\
\hline Galiana y Vejarano & $11 / 07 / 1922$ & $21 / 09 / 1922$ \\
\hline Marles y Serra & $16 / 01 / 1922$ & $28 / 04 / 1922$ \\
\hline Freixas y Delclaux & $15 / 12 / 1921$ & $17 / 12 / 1921$ \\
\hline
\end{tabular}

Fuente: Elaboración propia a partir de la información recogida en el AMMB, fondos JOP, caja H-1723. Carpeta «Almacenes de útiles y enseres de pesca en el muelle de Levante».

38. Solicitud presentada por Vicente Galiana a la dirección de JOP de Barcelona el 11 de julio de 1922. El mismo objeto de solicitud para poder reanudar la actividad es presentada por la casa Canosa el 14 de abril de 1921 (AMMB, fondos JOP, H-1723. «Almacenes de útiles y enseres de pesca en el muelle de Levante»).

39. Rodríguez (1923, p. 184). Este autor señala que los 31 restantes estaban 10 en el sur de España y 21, en el norte. 
TABLA 4 - Empresa y flota en el puerto de Barcelona en 1925.

\begin{tabular}{|c|c|c|c|c|c|}
\hline Buques & $\begin{array}{c}\text { Año } \\
\text { construcción }\end{array}$ & $\begin{array}{c}\text { Año } \\
\text { matriculación }\end{array}$ & $\begin{array}{c}\text { Material } \\
\text { casco }\end{array}$ & TRB & $\begin{array}{c}\text { Empresa } \\
\text { propietaria }\end{array}$ \\
\hline Angelita & 1908 & 1922 & Acero & 256 & Pesca y \\
\hline Fina & 1907 & 1922 & Acero & 251 & Navegación \\
\hline José María (ex-Corythaix) & 1910 & 1922 & Acero & 279 & S.A. $\left({ }^{*}\right)$ \\
\hline Tito (ex-Martineta) & 1909 & 1922 & Hierro & 294 & \\
\hline Mercedes & 1907 & & Acero & 278 & \\
\hline Manín & 1907 & 1922 & Acero & 251 & \\
\hline Paco & 1908 & & Acero & 300 & \\
\hline Total & & & & 1.909 & \\
\hline Canosa & 1916 & 1922 & Acero & 316 & Vda. Ramón \\
\hline Cierto & 1915 & 1922 & Acero & 318 & Canosa \\
\hline Ramón & 1919 & 1923 & Acero & 323 & $\begin{array}{l}\text { (Benita } \\
\text { Gutiérrez) }\end{array}$ \\
\hline Total & & & & 957 & \\
\hline Francisco & 1915 & 1922 & Acero & 327 & Francisco \\
\hline Pedro (ex-Schipperke) & 1911 & 1922 & Acero & 322 & Freixas Pons \\
\hline Luis (ex-Lord Roberts) & 1900 & 1918 & Acero & 217 & $\begin{array}{l}\text { y Luis } \\
\text { Delclaux }\end{array}$ \\
\hline Total & & & & 866 & González \\
\hline Santa Adela & 1907 & 1923 & Hierro & 299 & \\
\hline Santa Ana & 1915 & 1924 & Acero & 322 & Marlés \\
\hline Santa Cristina (ex-Trier) & 1910 & 1922 & Acero & 324 & y Serra \\
\hline Santa Rosa (ex-Stalwart) & 1914 & 1922 & Acero & 334 & \\
\hline Total & & & & 1.279 & \\
\hline M. ${ }^{\text {a }}$ Dolores & 1915 & 1923 & Acero & 323 & Galiana \\
\hline Río Mesa & 1918 & & Acero & 275 & y Vejarano \\
\hline Total & & & & 598 & \\
\hline
\end{tabular}

Fuente: Elaboración propia a partir de la LOB del año 1925, Memoria Comercial de la Cámara de Comercio y Navegación de Barcelona del año 1927 y Rodríguez (1923, p. 184).

${ }^{*}$ ) Esta empresa, aunque tenía los barcos matriculados en San Sebastián, operaba desde el puerto de Barcelona a través de la sucursal constituída en 1920 en dicha ciudad.

Como ya hemos señalado, en este segundo renacer es evidente el protagonismo de cinco casas armadoras, que aglutinaban toda la flota pesquera de altura de Barcelona. ${ }^{40}$

40. «[...] Existen actualmente cinco instalaciones: la de la S.A. Pesca y Navegación, la de los Sres. Freixas y Delclaux, la de la Sra. Vda de Canosa, la de los Sres. Marlés y Serra y la 
La empresa más importante, por capacidad de captura, fue Pesca y Navegación S.A. Dicha firma había sido constituida en Barcelona en junio 1920, con un capital de 12.000 .000 pesetas. ${ }^{41}$ Adquirió 7 bous en Inglaterra, al primero, Angelita, se le sumaron Fina, Manín, José María, Malén, Tito y Paco. Forman parte principal de esta compañía: el conde de Figols, el conde de Mieres, Joan $\mathrm{M}^{\mathrm{a}}$ Coll y, como gerente, Daniel de Araoz, ingeniero de la Armada. La compañía nació con el propósito de instalar depósitos frigoríficos y otras dependencias que serán destinadas a la manipulación del pescado. ${ }^{42}$

Sin embargo, el nacimiento de dicha sociedad estuvo auspiciado por armadores vascos; la sociedad constituída en Barcelona funcionaba como una delegación de la sociedad fundada en San Sebastián. ${ }^{43}$ Esta última se había dado de alta el 8 de febrero de 1922 en San Sebastián y su gerente era Pedro Ciriza Lafuente. ${ }^{44}$ Sin embargo, los buques de la sociedad operaban desde el puerto de Barcelona, aunque matriculados en San Sebastián..$^{45}$ Cabría señalar la importancia de los envíos de pescado desde los puertos vascos a la ciudad de Barcelona dada su proximidad geográfica en relación con otros puertos, sobre todo en los meses de calor. ${ }^{46}$

Esta compañía entró en liquidación a principios del año 1924 (consúltese anexo, figura 3). En el año previo a su liquidación, la sociedad poseía, además de la flota compuesta por los 7 bous y dos vapores de cabotaje, oficinas en el muelle de Barcelona, así como una fábrica de hielo con una capacidad de producción de 20.000 kilogramos diarios, un taller de reparaciones, máquinas y departamento de aserrar maderas, cámaras para hielo y pescado y amplios almacenes. ${ }^{47}$ Dicha sociedad estaba en liquidación tras el acuerdo tomado el 4 de enero de 1924 en una Junta General Extraordinaria de accionis-

de D. Vicente Galiana, todas ellas han funcionado de un modo regular durante el pasado bienio» (Memoria de la Junta de Obras del Puerto de los años 1922-1923, p. 139).

41. Vida Marítima, . $^{\circ}$ 664, 10 de julio de 1920. El 18 de junio de 1920 se inscribe el alta de la sociedad en el registro de industria, declarando como objeto el «pescado fresco» (ACA. Fondos de Hacienda. HAC. Inv. 1-7507, folio 352).

En realidad, la sociedad constituida en Barcelona funcionaba como una delegación de la sociedad constituida en San Sebastián (La Vanguardia, 16 de febrero de 1926).

42. Catalunya Marítima, . $^{\circ}$ 9, 30 de marzo 1920.

43. En este sentido, cuando se publica la convocatoria para las juntas de accionistas, en ellas se recoge la dirección de la oficina central (Príncipe, 1, San Sebastián) y de la delegación (Caspe, 54, 3ㅇ. Barcelona) (La Vanguardia, 9 de marzo de 1921).

44. La sociedad se había inscrito en el Registro Mercantil de San Sebastián (Registro de Sociedades, Libro 32, Folio 101).

45. Consultando para los años 1920-1928 la sección de La Vanguardia que recogía las entradas y salidas diarias de buques del Puerto de Barcelona, puede comprobarse la existencia de entradas y salidas regulares de los barcos de la empresa en la Ciudad Condal.

46. Los envíos desde puertos gallegos o del sur peninsultar invertían hasta cuatro días en el transporte del pescado, lo que hacía inviable los envíos desde dichos puertos en las épocas más calurosas del año. En el caso de los puertos vascos se empleaban una media de 18 horas, lo que los convertía en la única alternativa en los meses de estío. Puede consultarse, Sinde (2014).

47. $A B C, 17$ de abril de 1926 . 
tas, por lo que se pusieron a la venta los siete buques de su propiedad junto con otros bienes, los cuales adquirió la sociedad Pescaderías Coruñesas S.A. - la cual dirigía Luis Lamigueiro, que era el mayor accionista — por 1.500 .000 pesetas. en diciembre de $1925 .{ }^{48}$ Tras la compra por parte de Lamigueiro de la sociedad, mantendrá Barcelona como puerto base hasta el año 1926, cuando traslada sus barcos al sur. El objetivo de este empresario con la compra de la compañía catalana era la de acceder al mercado catalán, toda vez que ya controlaba el mercado madrileño. Con ello, conseguiría integrar toda la cadena de distribución de pescado fresco en España.

Otra de las firmas de relevancia en esta nueva etapa fue Vda. de Canosa (Benita Gutiérrez). Como ya se ha señalado anteriormente, había iniciado el negocio Ramón Canosa Cierto, de origen gallego. Tras la liquidación de la sociedad que formó con J. Reboredo - Canosa y Reboredo- y la venta de toda la flota, Ramón Canosa adquirirá una flota nueva y seguirá con el negocio en solitario hasta el año 1921, en el que fallece. Será su viuda, Benita Gutiérrez Díaz, la que continuará con el negocio tras su fallecimiento, aunque será el hijo de ambos, Ramón Canosa Gutiérrez, el encargado de la gestión de la empresa (consúltese anexo, figura 1)

La tercera empresa formalizaba la relación entre Francisco Freixas Pons, como representante de la sociedad colectiva Freixas Hermanos, y Luis Delclaux González de la Mata (consúltese anexo, figura 2). El apellido Freixas llevaba vinculado a los negocios marítimos y pesqueros desde inicios del siglo XX. En estos años, además de armadores, actuaban como consignatarios con casilla en el Mercado Central de Pescado a través de Pedro Freixas Farigola, que disponía de varias casillas en dicho mercado. Recordemos que ya en el año 1901 la familia había adquirido una casilla en el Mercado Central de Pescado, imprescindible para poder ejercer de consignatario y realizar subastas en dicho mercado de las partidas de pescado.

El 3 de diciembre de 1926 Francisco Freixas Pons compró la parte de Luis Delclaux y los hermanos transformaron, el 18 de febrero de 1927, la antigua sociedad colectiva en Freixas Hnos S.A. ${ }^{49}$ La sociedad se mantuvo en funcionamiento bajo dicha razón social hasta el 31 de octubre de 1935, año en el que se hizo con el activo de la firma el sobrino de los hermanos Freixas Pons, Juan Freixas Abad, cuyo apoderado era su hermano Pedro Freixas Abad..$^{50}$

La cuarta sociedad constituida tras la guerra fue la de Galiana y Vejarano Sociedad en Comandita, cuyo gerente era Vicente Galiana Puchol. Esta

48. La Veu de Catalunya, 12 de diciembre de 1925.

49. AAMB, JOP, H-1723. Carpeta «Almacenes de útiles y enseres de pesca en el muelle de Levante». Los vapores pesqueros de esta firma aparecen registrados en las LOB a nombre de Ramón Freixas Pons y de Francisco Freixas Pons.

50. Los hermanos Juan, Pedro, Francisco y María Freixas Abad eran hijos de Juan Freixas Pons y de Salvadora Abad Roca. 
nueva firma, creada en 1922, implicaba la continuidad de la actividad del armador Vicente Galiana, que en esta ocasión se asoció con Félix Vejarano y Bernardo de Quirós. No obstante, en realidad Vicente Galiana estaba como representante de Vicente Galiana Sociedad en Comandita, mientras que Félix Vejarano representaba a la Compañía Pesquera Trasatlántica S.A. (consúltese figura $1 \mathrm{del}$ anexo). El capital social escriturado ascendía a 925.000 pesetas., compuesto por 925 acciones de 1.000 pesetas cada una, de las cuales el primer socio poseía 440 acciones, mientras el segundo, 485 acciones. ${ }^{51}$

Por último, Justo Marlés Vilarrodona (capitán de la marina mercante y gerente de la misma) y Enrique Serra Alén constituyeron Marlés y Serra Sociedad Comanditaria. Dicha sociedad se inscribió en el Registro Mercantil de Barcelona el 30 de mayo de 1921 con un capital de 490.000 pesetas, del que Justo Marlés aportó 70.000 pesetas y Enrique Serra, 30.000 pesetas, actuando ambos como socios colectivos. El resto del capital se colocaría entre socios comanditarios (un total de 78 acciones de 5.000 pesetas de valor nominal). ${ }^{52}$

Cabe señalar que, en este período, los armadores trataron de controlar la primera fase del proceso de comercialización, esto es, la venta al por mayor en el Mercado Central. Así, bien directa o indirectamente, disponían de casillas en dicho mercado. En el caso de Pesca y Navegación S.A., su gerente, Daniel Araoz Aréjula, adquirió en el año 1921 dos casillas para la venta al por mayor. ${ }^{53}$ Dichas casillas serían traspasadas con todos los activos de la empresa a Pescaderías Coruñesas S.A. Mientras que, en el caso de Canosa, el consignatario de todos sus buques era José Xampeny, mayorista con casilla en el Mercado Central de Pescado. ${ }^{54}$ Además, el citado mayorista también participaba como socio comanditario en la firma. En el caso de Freixas, los armadores de los buques pesqueros eran los hijos, mientras que los padres eran mayoristas en dicho mercado central. Al fallecer el padre, Pedro Freixas Farigola, en el año 1930, las casillas pertenecientes a este serán traspasadas a sus hijos. ${ }^{55}$ Por su parte, las otras dos firmas, aunque no tenían la propiedad

51. RMB, Registro Sociedades, tomo 198, folio 10, hoja 15644. Las 440 acciones de Vicente Galiana S. en C. se distribuían en función de la participación en la empresa: Vicente Galiana, 180 acciones; Antonio Lloret, 86 acciones; Mariano Martí, 54 acciones; Pedro Olivé, 49 acciones; Manuel Deschamps, Miguel López, Cristóbal Pequeroles y José Gilabert, 27 acciones cada uno; Ernesto Anastasio Pascual, Joaquín Sabater, José Campany y Francisco Tejerina, 10 cada uno. Mientras que en el caso de los socios de la Cía Pesquera Trasatlántica S.A., Félix Vejarano, 178 acciones; Juan Machintosh, 167 acciones; Manuel Núñez, 84 acciones; Laureano Colvila, 41 acciones, y Manuel Playa, 25 acciones.

52. RMB, Registro Sociedades, tomo 152, folio 38, hoja 14.364. Manuel de Bustamente, 10 acciones; Mercedes Gal, Manuel Ferrer y Francisco Ramís, 9 acciones cada uno; José Bruguera, Bernardo Guilleminas y Victor Serra, 5 acciones cada uno; Ramón Trabal, 7 acciones; y por último, José Xampeny y Concepción Casali, 6 acciones cada uno.

53. Gaceta Municipal de Barcelona, 2 de febrero de 1922, p. 111.

54. Gaceta Municipal de Barcelona, 3 de agosto de 1921, p. 599.

55. Ramón Freixas Pons se quedaría con la n. ${ }^{\circ} 13$ y Juan Freixas Pons con la n. ${ }^{\circ} 11$ (Gaceta Municipal de Barcelona, 7 de abril de 1930, p. 204). 
directa de ninguna casilla, en ambas participaban como socios capitalistas algún mayorista. La sociedad Galiana y Vejarano, tenían entre sus socios a dos consignatarios de pescado, Pedro Olivé y José Gilabert; mientras que en la compañía Marlés y Serra, tenía acciones José Xampeny. Por tanto, es evidente la existencia de fuertes vínculos entre la fase extractiva y la de comercialización en el tramo mayorista.

\section{La desaparición de la flota pesquera de altura del puerto de Barcelona}

A finales de los años veinte del siglo Xx el sector pesquero de altura español volvió a enfrentarse a otra gran crisis. Los costes de producción de las empresas armadoras registraron un crecimiento continuado y los precios del pescado en los mercados finales eran cada vez menores debido a una intensificación de la competencia en el subsector de distribución. ${ }^{56}$

En esos años se produce la quiebra de muchas empresas pesqueras integradas verticalmente, entre ellas Pescaderías Coruñesas S.A., la propietaria de Pesca y Navegación S.A. Esto obligó al gerente de la primera a tener que subastar los barcos al no poder hacer frente a una de las hipotecas que había suscrito con el Banco Anglo-Sud Americano de Barcelona, acreedor por la cantidad de 1.650 .000 pesetas más los intereses estipulados, suma garantizada con la hipoteca de los diez buques propiedad de la sociedad y el número II propiedad personal de Luis Lamigueiro. ${ }^{57}$ En este contexto, el 31 de octubre de 1928 la sociedad sacó a subasta pública los diez buques con sus aparejos. Fueron adquiridos, el 19 de febrero de 1929, por Ramón de Madariaga por 1.000 .000 pesetas. A partir de la venta de los activos productivos, el empresario se centró en la fase de comercialización. En Madrid mantendrá la gestión de las tiendas minoristas y en Barcelona constituyó Lamigueiro Comisiones S.A., cuyo objeto era la comercialización al por mayor de pescado a través de las tres casillas que poseía en el Mercado Central de Pescado, que fueron aportadas al capital de la recién creada sociedad, que comenzó sus operaciones el 22 de octubre de 1928 y estuvo operativa hasta el 9 de marzo de $1951 .{ }^{58}$

Las otras cuatro casas armadoras tampoco evitaron la crisis de producción que estaba sufriendo el sector en el resto del país en esos años: «...los

56. Giráldez (1996).

57. En $A B C, 25$ de septiembre de 1928, aparece publicado el edicto de suspensión de pagos de la empresa.

58. La sociedad se constituye con un capital de 100.000 pesetas, compuesto de 200 acciones de 500 pesetas cada una. A Luis Lamigueiro le corresponderían 40 acciones, al igual que el resto de los 4 socios: Agustín Carbó, Miguel Borrás Juve, Juan Blanque Freixas y Jaime Flamendi Simó (RMB, Registro Sociedades, tomo 245, folio 185, hoja 17.225). 
veinte barcos de altura pertenecientes a las cuatro casas domiciliadas en esta plaza, están todos amarrados». ${ }^{59}$ Galiana y Vejarano se liquidó el 31 de mayo de 1934, mientras que, en el caso de Marlés y Serra, la sociedad cambió de objeto social pasando a dedicarse al negocio naviero, bajo la denominación Naviera Marlés S.A. ${ }^{60}$

Por otra parte, durante la Guerra Civil fueron intervenidos parte de los buques que se mantenían activos (véase tabla 5). Esto, sumado a los bombardeos sobre el puerto de Barcelona, que en ocasiones afectaron a las instalaciones de las empresas pesqueras, llevó a que alguna de las restantes firmas optase por el abandono o la reducción de la actividad. ${ }^{61}$

TABLA 5 - Flota de las armadoras y fecha de devolución de las concesiones de espacios en el muelle de Levante.

\begin{tabular}{|c|c|c|c|c|c|}
\hline Empresa & $\begin{array}{l}\text { Flota } \\
1931\end{array}$ & $\begin{array}{l}\text { Flota } \\
1942\end{array}$ & $\begin{array}{l}\text { Flota } \\
1951\end{array}$ & $\begin{array}{l}\text { Flota } \\
1961\end{array}$ & $\begin{array}{l}\text { Fecha acta } \\
\text { devolución }\end{array}$ \\
\hline Vda de Canosa & $\begin{array}{l}\text { Canosa }\left(^{*}\right) \\
\text { Cierto }\left(^{*}\right)\end{array}$ & $\begin{array}{l}\text { Canosa } \\
\text { Cierto } \\
\text { Sta Adela }\end{array}$ & $\begin{array}{l}\text { Canosa } \\
\text { Cierto } \\
\text { Sta Adela }\end{array}$ & $\begin{array}{l}\text { Canosa } \\
\text { Cierto } \\
\text { Sta Adela }\end{array}$ & $23 / 06 / 1956$ \\
\hline $\begin{array}{l}\text { Galiana y } \\
\text { Vejarano } \\
\text { S. Comanditaria }\end{array}$ & $\begin{array}{l}\text { M.. Dolores (*) } \\
\text { Río Mesa }\end{array}$ & M. ${ }^{\text {a }}$ Dolores & & & 21/08/1939 \\
\hline $\begin{array}{l}\text { Marlés y Serra } \\
\text { S. Comanditaria }\end{array}$ & $\begin{array}{l}\text { Sta Adela }\left({ }^{*}\right) \\
\text { Sta Anna }\left(^{*}\right) \\
\text { Sta Cristina }\left(^{*}\right) \\
\text { Sta Eulalia }\left(^{*}\right) \\
\text { Sta Rosa }\left(^{*}\right)\end{array}$ & & & & 07/11/1934 \\
\hline $\begin{array}{l}\text { Freixas Hnos. } \\
\text { S.A. }\end{array}$ & $\begin{array}{l}\text { María }\left(^{*}\right) \\
\text { Pedro } \\
\text { Francisco } \\
\text { Juan } \\
\text { Ramoncín } \\
\text { Ramón Freixas }\left(^{*}\right)\end{array}$ & $\begin{array}{l}\text { María } \\
\text { Pedro } \\
\text { Francisco }\end{array}$ & María & & 13/02/1954 \\
\hline
\end{tabular}

Fuente: Elaboración propia a partir de la información recogida en el AMMB, fondos JOP, caja H-1723. Carpeta «Almacenes de útiles y enseres de pesca en el muelle de Levante» y de las LOB de los años correspondientes.

(*) Buques intervenidos según Boletín Oficial del Estado de 19 de febrero de 1939.

59. Barcelona Pesquera, septiembre de 1930, p. 13.

60. RMB, Registro Sociedades, tomo 491, folio 132, hoja 14.364.

61. En este sentido, tal y como se recoge en una instacia presentada por Juan Freixas Abad el 26 de marzo de 1939 al director de la JOP: «[...] que teniendo que reconstruir el mencionado tinglado derruido en parte por los bombardeos de la aviación, y teniendo el negocio al que se dedicaba mucho más reducido por la disminución de su flota pesquera, y mucho más ahora por no disponer de ningún pesquero, ya que los dos de que disponía se hallan hundidos [...] por lo que no necesita para continuar su industria el día de mañana toda la concesión de la que disfrutaba, por lo que SUPLICA tenga a bien dar de baja la ampliación de tinglado [...]» (AMMB, fondos JOP, H-1723. Carpeta «Almacenes de útiles y enseres de pesca en el muelle de Levante»). 
Tras la Guerra Civil solo dos casas armadoras seguirán activas: Canosa y Freixas (consúltese tabla 5). La primera mantuvo su flota hasta la década de los sesenta, mientras que la firma Freixas se fue deshaciendo paulatimante de su flota, enajenando el último vapor, María, en la década de los cincuenta. Sin embargo, otros puertos y flotas sufrieron las mismas circunstancias y ello no implicó el desmantelamiento progresivo de la flota pesquera de altura.

En una entrevista al armador Marlés, en Barcelona Pesquera, este hacía referencia a la imposibilidad de la existencia de una flota pesquera de altura en el puerto de Barcelona y destacaba como factor principal las preferencias del consumidor de la Ciudad Condal. En esta localidad el consumidor solo valoraba la merluza, frente a otras especies también capturadas por dicha flota. Esto implicaba que gran parte del pescado tenía que ser vendido a precios que, en ocasiones, no cubrían costes. ${ }^{62}$

También cabría señalar que tras la Guerra Civil cobra importancia el transporte por carretera, y recordemos que uno de los principales problemas para abastecer a la ciudad de Barcelona desde otros puertos era el pésimo estado y la mala conexión del transporte por ferrocarril. Esto sumado a lo señalado anteriormente, la preferencia del consumidor barcelonés por la merluza, posibilitaba el envío desde otros puertos de especies adaptadas al perfil de dicho consumidor.

Esta nueva opción de abastecerse desde otros puertos permite entender que los armadores barceloneses abandonasen la fase extractiva del negocio y mantuviesen su negocio vinculado a la fase de comercialización, más lucrativa y con menos costes fijos.

\section{Conclusiones}

En España la pesca de altura y gran altura surgió con la incorporación de barcos a vapor que usaban el arte de arrastre. Su mayor capacidad extractiva trajo consigo un aumento considerable del volumen de capturas. Se hizo necesario buscar nuevos caladeros donde faenar y expandir los mercados de venta.

En este trabajo se ha analizado el nacimiento y la evolución de esta pesca en el puerto de Barcelona. Haciendo uso de distintas fuentes, se ha descrito cómo se fue configurando el sector en la Ciudad Condal desde sus comienzos

62. «No és d'ara que a Barcelona no poden sostenir-s'hi els vapors de pesca d'altura i són tants els factors que contribuixen a aquesta impossibilitat, [...] aquí, en el nostre mercat altres peixos, com calet, lluernes, besugo, pagell, dento, etc., no hi tenen acceptació, i si alguna espècie d'aquestes el primer dia de l'arribada del barco, té un preu remunerador, el segon dia paga sols les despeses i al tercer s'hi perden diners» (Barcelona Pesquera, octubre de 1930, p. 15). 
en el año 1907, hasta los años previos a la Guerra Civil, momento en el que se empezó a desmantelar, paulatinamente, la flota. En primer lugar, debemos resaltar que las primeras iniciativas empresariales en este nuevo sector de negocio fueron auspiciadas por armadores del norte, principalmente, del puerto de A Coruña. La elección del puerto de Barcelona para el desempeño de su actividad estuvo motivada por la estrategia de expansión de las áreas de pesca y la búsqueda de nuevos mercados. La ciudad poseía uno de los mayores mercados de España con unos niveles de consumo en crecimiento y desde ella se podía acceder a las aguas de la costa africana.

Estas empresas foráneas intentaron eliminar a los intermediarios existentes en el proceso de comercialización, algo que no fue posible debido al poder que tenían los consignatarios (o mayoristas) locales del Mercado Central, donde obligatoriamente debía de ser vendido el pescado y cuyo proceso de venta estaba controlado por estos.

Posteriormente, se incorporaron armadores locales con vínculos empresariales y/o familiares en la primera fase del proceso de comercialización. Esto garantizaba la posibilidad de controlar la primera venta del producto tras el desembarco, que era la que determinaba el volumen de ingresos de la actividad extractiva. Cabe destacar, también, el papel activo que desempeñaron estos armadores en la apertura de los caladeros africanos, su principal zona de pesca.

El crecimiento paulatino de unidades operativas llevó a que se concentrase en esta ciudad una de las mayores flotas de bous de España en los años previos la Gran Guerra. No obstante, durante el período bélico dicha flota fue desmantelada, al igual que en otros puertos de España, debido al incremento de los costes de explotación y a la dificultad de acceso a los caladeros.

La actividad fue retomada a principios de los años veinte por empresarios vinculados previamente a la actividad pesquera y con control, directo o indirecto, sobre la fase de comercialización. Esto implicó la renovación total de las embarcaciones y que se volviese a concentrar en el puerto barcelonés una flota relevante de ámbito nacional.

Sin embargo, a finales de la década surgieron nuevamente problemas asociados a los altos costes operativos y a la caída de los precios finales. La rentabilidad obtenida con la actividad extractiva, en ocasiones, no permitía compensar la elevada carga de costes fijos y obtener beneficios. En este contexto, a lo largo de los años siguientes las compañías procedieron a la venta de su flota, aunque algunas de ellas mantuvieron el área de negocio comercial. Esta decisión se justifica teniendo en cuenta los bajos costes de estructura y las rentabilidades superiores asociadas a la actividad comercial. Debemos señalar que esto fue posible debido a las mejoras registradas en los medios de transporte que permitían disponer del producto, en condiciones óptimas, desde otros puertos. 


\section{Bibliografía}

BAs, C. (1985). «La pesca a Catalunya». Butlletí de la Institució Catalana d'Història Natural, 50, pp. 209-212.

Compan VÁzQuez, D. (1975). «La pesca marítima en España». Cuadernos Geográficos, 5-6, pp. 87-175.

Coull, J. R. (1998). «National, regional and local divergences within the Scottish fishing industry since 1800». International Journal of Maritime History, X, pp. 201-218.

EiroA Del Río, F. (1997). Historia y desarrollo de la pesca de arrastre en Galicia. Diputación da Coruña, A Coruña.

Ford, A. (1997). United Towing 1920-1990: A history. Hutton Press Ltd., Beverley.

García Domingo, E. (2007). «El impacto de la Primera Guerra Mundial en la marina mercante española: un apunte sobre el caso catalán (1914-1922)». Transportes, Servicios y Telecomunicaciones, 13, pp. 122-144.

GirÁldez Rivero, J. (1985). «Aproximaçom ao sector pesqueiro galego no primeiro terço do século XX». Agalia, monográfico n. ${ }^{\circ}$ 2, pp. 7-31.

- (1996). Crecimiento y transformación del sector pesquero gallego, 1880-1936. Ministerio de Agricultura, Pesca y Alimentación, Madrid.

- (2002). «Armadores de Cádiz: competir y cooperar». Revista de Historia Agraria, 28, pp. 91-112.

LACOMBA, J. A. (2006). El sector pesquero andaluz en el último cuarto del siglo XIX: una fase de cambios y transformaciones. Revista de Estudios Regionales, 75, pp. 129-152.

Lledó Martín, J. (1941). La pesca nacional. Pegaso, Madrid.

LóPEz LosA, E. (1997). «Recursos naturales, derechos de propiedad y cambio técnico. La difusión del arrastre a vapor en las pesquerías vascas, 1878-1936». En LóPEz GARCÍA, S.; VAldaliso, J.M. (1997) (eds.). ¿Qué inventen ellos? Tecnología, empresa y cambio económico en la España contemporánea. Alianza Universidad, Madrid, pp. 157-209.

- (1999). «The technical change in the Basque fisheries: the diffusion of steam trawling 1878-1936». En Holm, P.; STARKey, D. J. (eds.). Technological change in the North Atlantic fisheries. Studia Atlantica, Esbjerg.

MARtínez Milán, J. M. (2005). «La flota artesanal canaria en el caladero sahariano: crecimiento sin cambio técnico (1880-1945)». En Congreso de la Asociación de Historia Económica.

- (2014). «Las inversiones del Estado español en la industria derivada del pescado en el área sahariano-mauritana, 1946-1980». Revista de Historia Industrial, 54, pp. 107-137.

Maiz Alkorta, J.A. (1993). El sector pesquero vizcaíno, 1800-1960. Análisis de la interacción de los elementos ambiental, extractivo y comercial en la pesquería (tesis doctoral). Universidad de Deusto-Bilbao.

Mirás Araujo, J. (2005). «La pesca y sus fluctuaciones en el puerto de A Coruña». Revista de Historia Agraria, 37, pp. 489-511. 
Mitichov, N. W.; LAPshin, R. W. (2011). «Los bous de procedencia española incorporados a la flotilla del Océano Glacial Ártico durante la Primera Guerra Mundial». Revista General de la Marina, 261, pp-873-881.

Moreno Rico, F.J. (2011): El capitán de Marina Mercante José Ricart y Girald (18471930). Una aproximación a la historia marítima contemporánea de Barcelona (tesis doctoral). Universidad Politècnica de Catalalunya.

Mumby-Croft, R. (2001). «Investment and decision making in the UK distant water fishing industry: a case study of the Consolidated Steam Fishing and Ice Company 1905-1980». Management Decision, 39, pp. 78-85.

OCAMPO SuÁREZ-VALDÉS, J. (2002). «Cambio técnico e industrialización pesquera en Asturias (1880-1936)». Revista de Historia Agraria, 28, pp. 69-90.

- (2003). «Ferrocarril, mercado e industrialización en Asturias: el sector pesquero y conservero, 1880-1930». En Actas del III Congreso de Historia Ferroviaria. Siglo y medio de ferrocarril en Asturias, 23-26 de septiembre, pp. 1-17.

Quiroga, D. (1952). «La Coruña Pesquera». Industrias Pesqueras, 601-602, pp. 48-54.

Ríos JiMÉNEZ, S. (2002). «La industrialización de la pesca en la provincia de Huelva, 1800-1930». Revista de Historia Agraria, 28, pp. 45-67.

RoBINSON, D. J. (1998). «The diffusion of steam in the fishing industries of northwest Europe». International Journal of Maritime History, X, pp. 179-200.

Robinson, R. (1996). Trawling. The rise and fall of the British trawl fishery. University of Exeter Press, Exeter.

Rodríguez Santamaría, B. (1923). Diccionario de artes de pesca de España y sus posesiones. Sucesores de Rivaneyra, Madrid.

Sinde CANTORnA, A.I. (1999). «El transporte de pescado en España y el problema de los vagones frigoríficos 1890-1950». En MuÑoz Rubio, M.; SAnZ FERnÁndeZ, J.; VidAL Olivares, J. (eds.). Siglo y medio de ferrocarril en España 1848-1998. Economía, industria y sociedad. Fundación de Ferrocarriles Españoles, Alicante, pp. 771-786.

- (2000). Estrategias de crecimiento y formas de integración en la empresa pesquera gallega: 1900-1960. Fundación de Empresa Pública, Documento de trabajo 2002, Madrid.

- (2014). «El abastecimiento de pescado fresco en Barcelona: 1890-1941. Una primera aproximación». Comunicación presentada en el XI Congreso de la Asociación de Historia Económica. Sesión 11.

Sinde Cantorna, A. I.; Diéguez Castrillón, M.I. (2006). «Cooperation vs. vertical integration in Galicia's distant water fishing industry. A case study of A Coruña fishing companies, 1900-1950». En International Journal of Maritime History, XVIII, pp. 219-236.

Thompson, M.; Newton, D.; Robinson, R.; Lofthouse, T. (1999). Cook, Welton \& Gemmel shipbuilders of Hull and Beverley 1883-1963. Hutton Press Ltd., Beverley

Valdaliso Gago, J. M. (1991). Los navieros vascos y la Marina Mercante en España, 1860-1935. Una historia económica. IVAP, Bilbao. 
VeigA, B. (1974). Arcomar. 50 Aniversario (1923-1973). Arcomar, Cádiz.

Wilcox, M. (2012). «Railways, roads and the British white fish industry». Business History, 54, pp. 741-764.

\section{ANEXO}

FIGURA 1 - Casa Canosa

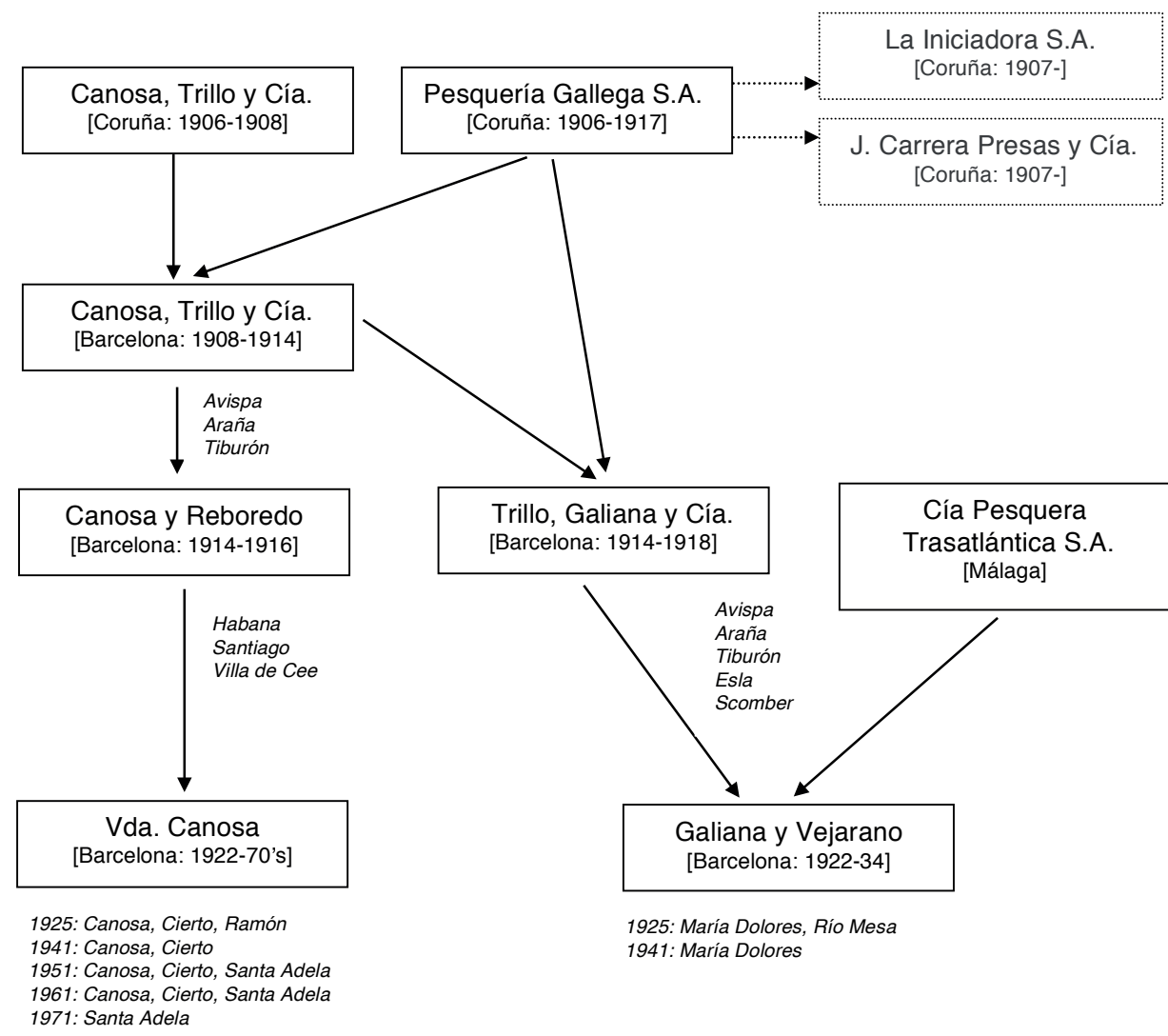


FIGURA 2 - Casa Freixas

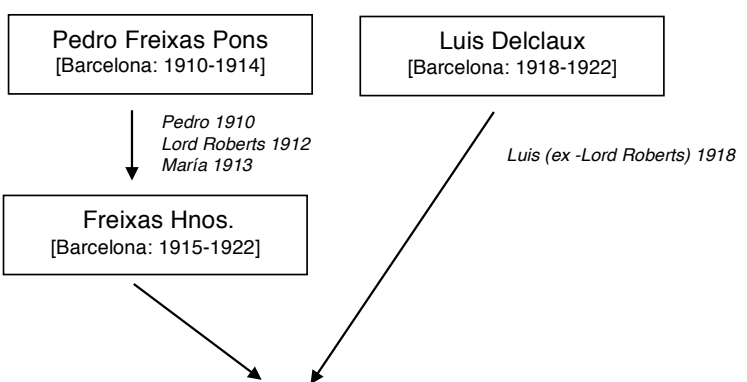

Freixas y Delclaux [Barcelona: 1922-1926]

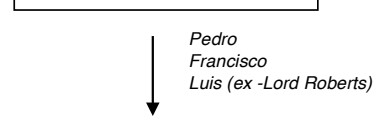

Freixas Hnos. S.A

[Barcelona: 1927-1936]

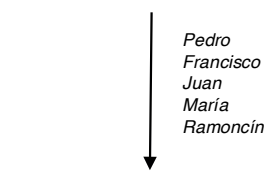

Juan Freixas Abad

[Barcelona: 1935-50's]

1941: Pedro, Francisco, María 1951: María 
FIGURA 3 - Pesca y Navegación S.A.

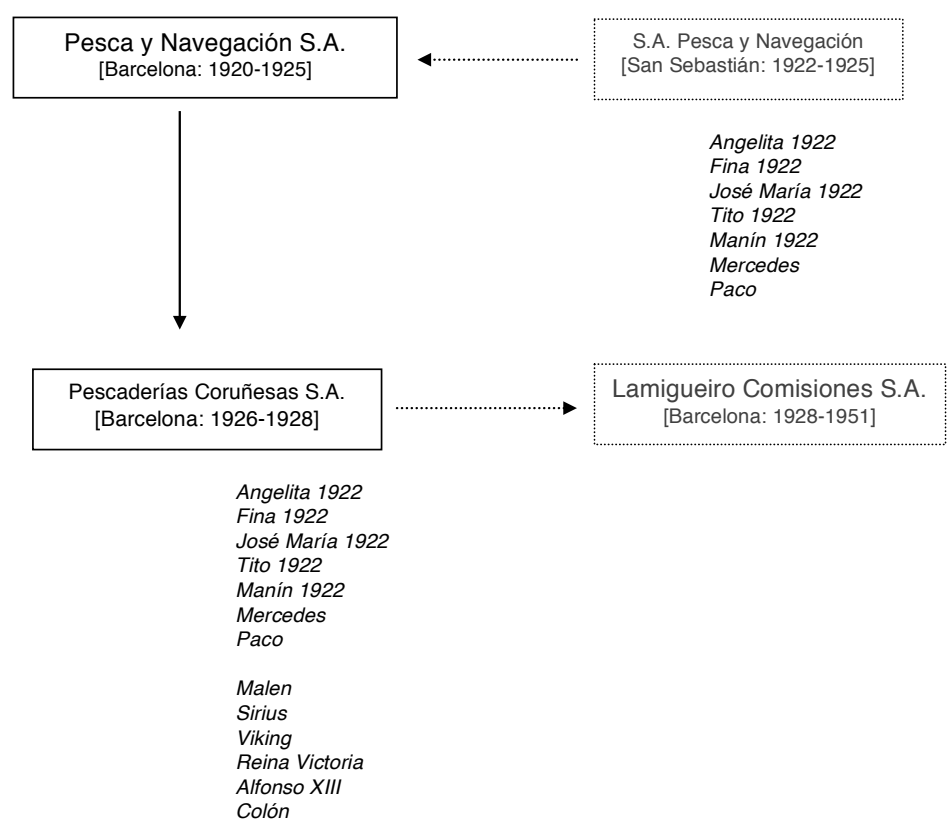




\title{
The fishing fleet in the port of Barcelona. An untold story (1907-1936)
}

\begin{abstract}
The adoption of trawling was studied for different Spanish ports, but not for the port of Barcelona. This has led to the consideration that the fishing fleet based there was minor. However, in this paper a study on the number moored vessels and businesses tied to their management is performed. Thus, it is concluded that, although from the 1930s it may have ceased to be representative, it was not until that date. Between 1907 and the years before the Civil War the port of Barcelona had one of the largest and most modern fleets in the Peninsula, covering an important part of the consumption of fresh fish in the city. Likewise, companies in charge of its management were also involved in distribution activities.
\end{abstract}

KEYWORDS: fishing firms, fishing industry, Barcelona

JEL CODES: L22, N54, Q22

\section{La flota pesquera de altura y gran altura en el puerto de Barcelona. Una historia no contada (1907-1936)}

\section{RESUMEN}

La adopción de vapores de arrastre fue estudiada para diferentes puertos españoles, pero no para el puerto de Barcelona. Esto ha llevado a considerar que la flota pesquera de altura allí asentada fue de escasa importancia. Sin embargo, en este trabajo se realiza un estudio sobre el número de unidades amarradas y las empresas que las gestionaron. Con ello, se concluye que, si bien a partir de los años treinta sí deja de ser representativa, no es así hasta esa fecha. Entre 1907 y los años previos a la Guerra Civil el puerto de Barcelona disponía de una de las flotas más importantes y modernas de la Península, que cubría una parte importante del consumo de pescado fresco en dicha ciudad. Así mismo, las empresas encargadas de su gestión trataron de controlar las actividades de distribución.

PALABRAS CLAVE: empresas pesqueras, pesca industrial, Barcelona

Códigos JEL: L22, N54, Q22 